\title{
Thermal effects of headgear: state-of-the-art and way forward
}

\author{
Cornelis C Bogerd ${ }^{1 *}$, Jean-Marie Aerts ${ }^{2}$, Simon Annaheim³ ${ }^{3}$, Peter Bröde ${ }^{4}$, Guido de Bruyne ${ }^{5}$, Andreas D Flouris ${ }^{6}$, \\ Kalev Kuklane, ${ }^{7}$ Tiago Sotto Mayor ${ }^{3}$, René M Rossi ${ }^{3}$, TU1101 WG4 Action COST ${ }^{8}$
}

From 15th International Conference on Environmental Ergonomics (ICEE XV)

Portsmouth, UK. 28 June - 3 July 2015

\section{Introduction}

Headgear is widely used in both work and leisure. Much research attention has been spent on optimizing impact properties of helmets [1], [2]. However, thermal comfort of headgear is suboptimal in neutral and warm environments. In fact, thermal discomfort is often given as a reason to not wear protective headgear [3], [4]. Enhanced thermal comfort of headgear is likely to improve the willingness to wear protective headgear, and motivated an increasing number of studies, of which most were published in the last decade. The available body of literature allows for a valuable first review on the thermal effects of headgear.

\section{Methods}

The literature on thermal effects of headgear was reviewed for the purpose of providing a sound basis for improving helmet design, and for effective future studies.

\section{Results}

Four topics will be addressed: (i) the effect on thermal physiology, health and performance, (ii) heat and mass transfer, (iii) methods for studying thermal effects of headgear, (iv) design considerations (Bogerd et al., 2015). Several topics will be detailed by other contributions to this conference from COST Action TU1101, which enhances the accessibility of the subject on ergonomics of headgear for the audience of this conference. collaboration and discussions. COST is supported by the EU Framework Programme for Research and Innovation Horizon 2020.

\section{Authors' details}

${ }^{1}$ CBRN Protection, TNO, the Netherlands. ${ }^{2}$ Division Measure, Model \& Manage Bioresponses, KU Leuven, Belgium. ${ }^{3}$ Laboratory for Protection and Physiology, Empa, Switzerland. ${ }^{4}$ Leibniz Research Centre for Working Environment and Human Factors (IfADo), Dortmund, Germany. ${ }^{5}$ Product Development, Faculty of Design Sciences, University of Antwerp, Belgium. ${ }^{6}$ FAME Laboratory, University of Thessaly, Greece. ${ }^{7}$ Department of Design Sciences, Lund University, Sweden. ${ }^{8} \mathrm{HOPE}-$ Helmet OPtimization in Europe, EU COST Action TU1101 Working Group 4 (http://www.bicycle-helmets.eu.

Published: 14 September 2015

\section{References}

1. Deck C, Willinger R: Multi-directional optimisation against biomechanical criteria of a head-helmet coupling. Int J Crashworthiness 2006, 11:561-572.

2. Mills N, Gilchrist A: Oblique impact testing of bicycle helmets. Int J Impact Eng 2008, 35:1075-1086.

3. Orsi C, Stendardo A, Marinoni A, Gilchrist MD, Otte D, Chliaoutakis J, Lajunen T, Özkan T, Pereira JD, Tzamalouka G, Morandi A: Motorcycle riders' perception of helmet use: Complaints and dissatisfaction. Accid Anal Prev 2012, 44:111-117, doi:10.1016/j.aap.2010.12.029.

4. Patel R, Mohan D: An improved motorcycle helmet design for tropical climates. Appl Ergon 1993, 24:427-431.

5. Bogerd CP, Aerts JM, Annaheim S, Bröde $P$, de Bruyne G, Flouris AD, Kuklane K, Sotto Mayor T, Rossi RM: A review on ergonomics of headgear: Thermal effects. Int J Ind Ergon 2015, 45:1-12, doi:10.1016/j. ergon.2014.10.004

doi:10.1186/2046-7648-4-S1-A71

Cite this article as: Bogerd et al:: Thermal effects of headgear: state-ofthe-art and way forward. Extreme Physiology \& Medicine 2015 4(Suppl 1): A71.

\section{Acknowledgements}

We are grateful to our colleagues from COST Action TU1101 "Towards safer bicycling through optimization of bicycle helmets and usage" for fruitful

\footnotetext{
* Correspondence: niels.bogerd@tno.nl

${ }^{1}$ CBRN Protection, TNO, the Netherlands

Full list of author information is available at the end of the article
} 